\title{
Inspiratory Flows and Volumes in Subjects with Non-CF Bronchiectasis Using a New Dry Powder Inhaler Device
}

\author{
Mark R. Elkins ${ }^{1}$, Sandra D. Anderson ${ }^{1}$, Clare P. Perry ${ }^{1}$, Evangelia Daviskas ${ }^{1}$ and \\ Brett Charlton ${ }^{*}, 2$
}

${ }^{1}$ Royal Prince Alfred Hospital, Sydney, Australia

${ }^{2}$ Pharmaxis Ltd, Sydney, Australia

\begin{abstract}
Introduction: Drug inhalation via a dry-powder inhaler (DPI) is a convenient, time efficient alternative to nebulizers in the treatment of cystic fibrosis (CF) or non-CF bronchiectasis. Efficient drug administration via DPIs depends on the device resistance and adequate $(\geq 45 \mathrm{~L} / \mathrm{min})$ inspiratory flows and volumes generated by individuals. Drypowder mannitol is delivered using a RS01 breath-actuated device developed by Plastiape, for Pharmaxis. The study aim was to determine in vivo if non-CF bronchiectasis patients' inspiratory flows and volumes are adequate to use the RS01 DPI device.
\end{abstract}

Materials and Methodology: An open, non-interventional study; enrolled 17 subjects with non-CF bronchiectasis, 18 to 80 years, with baseline $\mathrm{FEV}_{1} \geq 1.0 \mathrm{~L}$ and $\geq 50 \%$ predicted. Inspiratory flows and volumes were measured when subjects inhaled in a controlled manner through the RS01 device in series with a spirometer.

Results: The mean inspiratory volume (IV) of non-CF bronchiectasis subjects was $2.08 \pm 0.5 \mathrm{~L}$ and achieved a mean PIF of $78.6 \pm 11.2 \mathrm{~L} / \mathrm{min}$ with the inhaler device.

Conclusion: Use of the RS01 DPI device allowed adequate inspiratory flow and volume for dispersion of dry-powder mannitol in non-CF bronchiectasis patients.

Keywords: Bronchiectasis, clinical trials, respiratory function tests, dry powder inhaler, high resistance inhaler, peak inspiratory flow.

\section{INTRODUCTION}

Inhalation of dry powder formulations via a dry-powder inhaler (DPI) is a convenient and time-efficient alternative to inhalation of wet aerosols via nebulizers in the treatment of respiratory diseases such as cystic fibrosis (CF) or bronchiectasis. Generally, adequate administration of drugs via DPIs depends on the resistance of the device and adequate inspiratory flows and volumes generated by individuals. These may vary according to the device being used for a particular formulation and the patient's lung function impairment.

Encapsulated precision spray-dried mannitol for inhalation is used in the currently registered diagnostic product $\mathrm{Aridol}^{\circledR} / \mathrm{Osmohale}^{\circledR}$ to identify bronchial hyperresponsiveness as well as in the CF therapeutic Bronchitol ${ }^{\mathbb{R}}$. It is also being used in clinical trials as a potential treatment in subjects with non-CF bronchiectasis. Each Bronchitol ${ }^{\mathbb{B}}$ capsule (gelatin size 3) contains $40 \mathrm{mg}$ of spray-dried mannitol powder with no excipients. Spray-dried mannitol powder consists of particles that are of respirable size [1] $(<5 \mu \mathrm{m}$ in diameter) in sufficient quantity and spherical in

*Address correspondence to this author at Pharmaxis Ltd., 20 Rodborough Road, Frenchs Forest NSW 2086, Australia; Fax: +61 29451 3622;

E-mail: brett.charlton@pharmaxis.com.au shape to allow them to disperse well in an aerosol. The mannitol dose, $400 \mathrm{mg}$ (10x40 $\mathrm{mg}$ capsules), required to generate a significant osmotic effect in the lung, can be delivered in less than 5 minutes by a simple hand-held DPI, which requires no power source and provides a convenient and hygienic delivery system.

A convenient and efficient breath-actuated portable device, the dry powder inhaler type RS01 Model 7, manufactured by Plastiape S.p.A. Via 1 Maggio 8, 23875 Osnago-Lecco in Italy (CE marked) (Fig. 1A-D), has been approved for use with dry-powder mannitol. Two versions of the RS01 device are available and have been approved for use with two dry-powder mannitol products for inhalation, Aridol $^{\circledR}$ and Bronchitol ${ }^{\circledR}$; the low resistance (LRes) inhaler with mean resistance $0.021 \mathrm{kPa}^{1 / 2} / \mathrm{L}$ min used in the mannitol bronchial challenge test $\left(\operatorname{Aridol}^{\mathbb{B}}\right)$ and some earlier bronchiectasis studies, and a high resistance (HRes) inhaler with mean resistance of $0.036 \mathrm{kPa}^{1 / 2} / \mathrm{L}$ min which has been trialled and marketed in CF patients and is now being trialled in studies with non-CF bronchiectasis patients [Pharmaxis data on file]. The only difference between the two devices relates to the diameter of the air inlet ports on each side of the inhaler. The HRes has a flange that restricts the flow, resulting in a slightly higher resistance (Fig. 1D).

The choice to study and market the HRes device with Bronchitol when it is used therapeutically was made based 


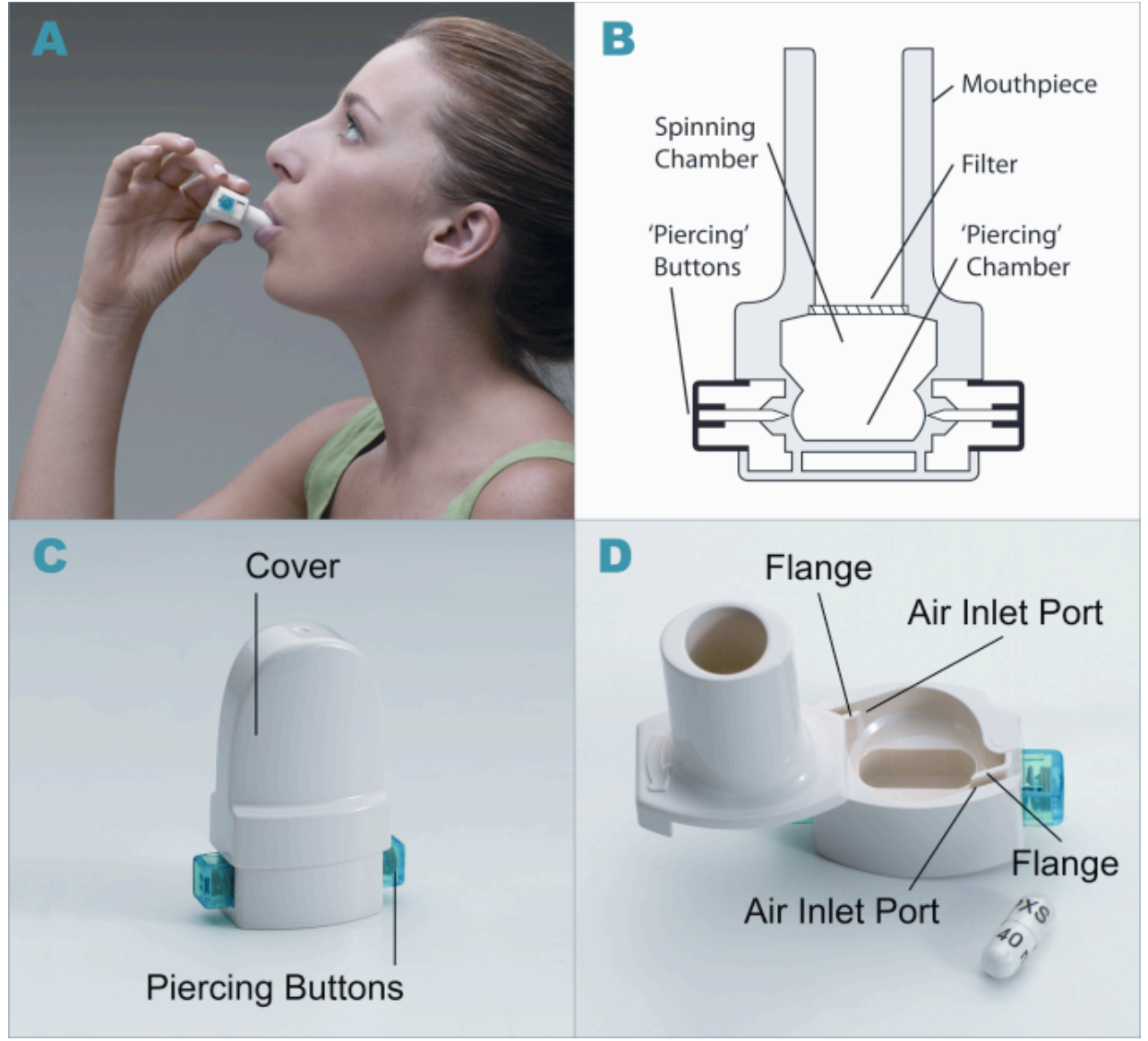

Fig. (1). Dry powder inhaler type RS01 model 7. (A) How to use the inhaler device. (B) Representation of the inhaler device. (C) HRes Inhaler with cover and showing piercing buttons. (D) HRes Inhaler showing air inlets and cavity for capsule.

on patient feedback in clinical studies, which indicated that the HRes provided better ease of use and tolerability than the LRes device in CF and non-CF bronchiectasis.

Depending on the degree of lung function impairment, non-CF bronchiectasis patients may not be able to generate optimal flows or volumes for drug delivery through the HRes RS01 DPI. We conducted an open observational nondrug study to confirm the usability of the new dry-powder inhaler RS01 in adult subjects with non-CF bronchiectasis, all of whom had inspiratory flow and volumes in the range eligible to use the product [Pharmaxis data on file]. The objective of this study was to measure the inspiratory flows and volumes generated by subjects inhaling through the device.

\section{STUDY OBJECTIVES}

The primary objective of the study was to determine the inspiratory flow of subjects with non-CF bronchiectasis using the HRes RS01 DPI device.

The secondary objective was to determine inspiratory volumes in non-CF bronchiectasis subjects using the HRes RS01 DPI device.

\section{MATERIAL AND METHODS}

\subsection{Recruitment}

Subjects were recruited from one Australian centre. All patients provided written informed consent.

\subsection{Inclusion / Exclusion Criteria}

The subjects eligible to participate were:

- Subjects with evidence of confirmed diagnosis of non-CF bronchiectasis by HRCT, CT, bronchogram or lobectomy, aged between 18 and 80 years (inclusive), with a baseline $\mathrm{FEV}_{1} \geq 50 \%$ predicted [2] and $\geq 1.0 \mathrm{~L}$. Subjects also had chronic cough and sputum production of $>10 \mathrm{~mL}$ per day on the majority of days in the 3 months prior to study entry and chronic chest congestion which was defined as chronic excessive accumulation of mucus in the lungs. Patients were required to be in a stable condition for a period of 14 days prior to recruitment into the study.

Exclusion criteria included subjects who had bronchiectasis as a consequence of cystic fibrosis or focal endobronchial lesion, active signs and symptoms of asthma, or previously demonstrated airway hyperresponsiveness to mannitol. They were also excluded if they were considered "terminally ill" or listed for lung transplantation or were lung transplant recipients. Myocardial infarction, cerebral vascular accident, major ocular, abdominal, chest or brain surgery in the three months prior to enrolment were exclusion criteria as they are a contraindication to the performance of spirometry. Also, known cerebral, aortic or abdominal aneurysm, breast feeding or pregnant subjects or those using beta blockers or who had any other condition 
which in the investigator's opinion may put the subject at significant risk, confound results or interfere significantly with the patient's participation in the study, were excluded.

\subsection{Sample Size}

Due to the exploratory nature of this study no formal sample size calculations were performed.

\subsection{Study Design}

A Phase IV, observational, open label, non-interventional single visit, single centre clinical study primarily measuring the inspiratory flow through the HRes RS01 inhaler device in a group of non-CF bronchiectasis subjects. (ClinicalTrials.gov Number NCT00656565)

At baseline each potential subject was examined to determine eligibility for the study. This included written informed consent, collection of their respiratory history and demographic information and measurement of $\mathrm{FEV}_{1} \%$ predicted.

\subsection{Setting}

Data were collected in one tertiary hospital in Sydney, Australia.

\subsection{Outcomes}

The following measures were collected: PIF, $\mathrm{IF}_{25}, \mathrm{IF}_{50}$, $\mathrm{IF}_{75}$, IV and $\mathrm{IV}_{1}$.

\subsection{Study Protocol}

A standard spirometer (calibration checked daily) was used to measure the forced expiratory volume in one second $\left(\mathrm{FEV}_{1}\right)$ according to ATS/ERS criteria [3]. The spirometer used was a Micro Medical SpiroUSB ${ }^{\text {TM }}$ Cat. ML2525 (CareFusion). The same spirometer was used for all subjects.

Spirometry was conducted with the subjects seated in a comfortable position. Subjects were given an opportunity to practice the technique inspiring comfortably at $60 \mathrm{~L} / \mathrm{min}$. The HRes RS01 DPI device, containing an empty but unpierced capsule, was placed in series with the spirometer, allowing the inspiratory flows and volumes to be recorded on a computer. In this study an empty capsule was employed in lieu of a $40 \mathrm{mg}$ capsule of Bronchitol. An empty capsule is similar to the empty device and dummy device methods employed by other researchers when measuring flows through new devices. The empty unpierced capsule was changed between each inspiration. The subjects were instructed to exhale away from the device then place the mouthpiece in their mouth and create a firm seal with their lips. The subjects took 3 to 5 steady deep controlled inspirations using the HRes inhaler and the inspiratory flow and volume were measured during each inspiration. Inspiratory flow measures including PIF, $\mathrm{IF}_{25}, \mathrm{IF}_{50}$, and $\mathrm{IF}_{75}$ were calculated using three out of five inhalations following the study procedure. The mean of the three trials having the greatest PIF of the five trials performed was used for the following inspiratory measures: PIF, $\mathrm{IF}_{25}, \mathrm{IF}_{50}, \mathrm{IF}_{75}, \mathrm{IV}$ and $\mathrm{IV}_{1}$.

\subsection{Safety}

During this non-interventional study, all subjects underwent the same testing which involved an inspiratory manoeuvre (three to five deep, controlled inspirations) via a spirometer to which the DPI device containing empty, unpierced capsules was placed in series. The measurements were made at one visit only and the subjects were not administered a drug or any intervention. All adverse events which occurred during the inhalations and up to 15 minutes after completion were recorded by the investigator.

\subsection{Statistical Analyses}

Descriptive statistics of continuous measures consist of the number of observations (n), mean, standard deviation (SD), median, minimum and maximum values and $95 \%$ confidence intervals. Categorical variables are described using counts of frequency and percentage of group $(n(\%))$.

Peak inspiratory flow (PIF) and maximal inspiratory flows at $25 \%, 50 \%$ and $75 \%$ of maximal inspiratory volume $\left(\mathrm{IF}_{25}, \mathrm{IF}_{50}\right.$ and $\left.\mathrm{IF}_{75}\right)$ are summarised and tabulated overall and by baseline $\mathrm{FEV}_{1}$ groups; with $70 \%$ predicted being the dividing point $(<70 \%, \geq 70 \%)$. A two independent sample ttest was used to determine whether differences exist between $\mathrm{FEV}_{1}$ groups for each measure.

\subsection{Ethics}

The study was approved by the Sydney South West Area Health Service, Ethics Research Committee, Sydney, Australia prior to commencement of the study. Patients provided written informed consent for their participation in the study.

\section{RESULTS}

\subsection{Patient Demographics and Disposition}

Seventeen subjects diagnosed with non-CF bronchiectasis were enrolled and all completed the study (Table 1). Five of the subjects had a baseline $\mathrm{FEV}_{1}<70 \%$ predicted and the remaining 12 subjects had $\mathrm{FEV}_{1} \geq 70 \%$ predicted (Table 1).

Table 1. Baseline Characteristics (All Subjects)

\begin{tabular}{|c|c|c|c|}
\hline \multirow[t]{2}{*}{ Parameter } & \multicolumn{3}{|c|}{ Non-CF Bronchiectasis } \\
\hline & $\begin{array}{c}\text { Overall } \\
(n=17)\end{array}$ & $\begin{array}{c}\text { FEV }_{1}<70 \% \\
\text { pred } \\
(n=5)\end{array}$ & $\begin{array}{c}\mathrm{FEV}_{1} \geq 70 \% \\
\text { pred } \\
(\mathrm{n}=12)\end{array}$ \\
\hline \multicolumn{4}{|l|}{ Age, years: } \\
\hline Mean (SD) & $60.4(11.3)$ & $64.0(6.0)$ & $58.8(12.9)$ \\
\hline [Range] & {$[22-72]$} & {$[57-72]$} & {$[22-69]$} \\
\hline \multicolumn{4}{|l|}{ Gender: } \\
\hline Male & $2(12 \%)$ & $2(40 \%)$ & 0 \\
\hline Female & $15(88 \%)$ & $3(60 \%)$ & $12(100 \%)$ \\
\hline \multicolumn{4}{|l|}{$\mathrm{FEV}_{1}(\mathrm{~L})$} \\
\hline Mean (SD) & $1.77(0.50)$ & $1.25(0.13)$ & $1.91(0.49)$ \\
\hline [Range] & {$[1.05-2.77]$} & {$[1.05-1.91]$} & {$[1.29-2.77]$} \\
\hline Median & 1.65 & 1.29 & 1.83 \\
\hline \multicolumn{4}{|l|}{$\mathrm{FEV}_{1}(\%$ predicted $)$} \\
\hline Mean (SD) & $78.1(17.4)$ & $57.8(5.93)$ & $86.6(12.7)$ \\
\hline [Range] & {$[52-114]$} & {$[52-67]$} & {$[71-114]$} \\
\hline Median & 78 & 56 & 85 \\
\hline
\end{tabular}


Table 2. Mean (SD) Inspiratory Flows and Volumes in Non-CF Bronchiectasis Subjects

\begin{tabular}{|c|c|c|c|c|c|}
\hline \multicolumn{6}{|c|}{$\begin{array}{c}\text { Parameters } \\
\text { Mean (SD) } \\
\text { Range }\end{array}$} \\
\hline $\begin{array}{c}\text { PIF } \\
\text { (Lmin) }\end{array}$ & $\begin{array}{c}\mathbf{I F}_{25} \\
(\mathbf{L} / \mathbf{m i n})\end{array}$ & $\begin{array}{c}\mathbf{I F}_{50} \\
(\mathbf{L} / \mathbf{m i n})\end{array}$ & $\begin{array}{c}\mathbf{I F}_{75} \\
(\mathbf{L} / \mathbf{m i n})\end{array}$ & $\begin{array}{l}\text { IV } \\
\text { (L) }\end{array}$ & $\begin{array}{l}I_{V_{1}} \\
(L)\end{array}$ \\
\hline $\begin{array}{l}78.6(11.2) \\
58.8-99.6\end{array}$ & $\begin{array}{l}75.6(11.7) \\
56.4-96.0\end{array}$ & $\begin{array}{l}71.4(11.5) \\
49.8-94.8\end{array}$ & $\begin{array}{l}56.4(10.3) \\
37.2-78.0\end{array}$ & $\begin{array}{l}2.08(0.51) \\
1.24-3.05\end{array}$ & $\begin{array}{l}1.09(0.17) \\
0.78-1.36\end{array}$ \\
\hline
\end{tabular}

PIF - Peak inspiratory flow, $\mathrm{IF}_{25}$ - Inspiratory flow at $25 \%$ inspiratory volume, $\mathrm{IF}_{50}-$ Inspiratory flow at $50 \%$ inspiratory volume, $\mathrm{IF}_{75}-\mathrm{Inspiratory}_{\mathrm{flow}}$ at $75 \%$ inspiratory volume, IV - Inspiratory volume, $\mathrm{IV}_{1}$ - Inspiratory volume in 1 second.

\subsection{Lung Function}

The inspiratory flows and volumes achieved are shown in Table 2 and illustrated in Figs. (2, 3). Only one subject (6\%) had a PIF less than $60 \mathrm{~L} / \mathrm{min}$. All subjects generated a PIF $>45 \mathrm{~L} / \mathrm{min}$

\subsection{Adverse Events and Device Utility}

All subjects were able to operate the HRes RS01 inhaler easily with minimal advice regarding technique. No adverse events were reported and no other safety issues arose during the studies.

\section{DISCUSSION}

The findings support the use of the HRes RS01 device for delivering dry powder mannitol to the lower airways in subjects with non-CF bronchiectasis.

The important determinants for optimal dispersion of drugs via DPI are the device resistance and the inhalation flow and volume of the subjects [4-9]. The resistance of the RS01 HRes device of $0.036 \mathrm{kPa}^{1 / 2} / \mathrm{L}$ min is within the range of the resistance of DPIs used for delivering other dry powder formulations to the lung [4,5]. The flows that the patients generate inhaling through the device are of critical importance as they provide the energy for optimal dispersion of the powder [5]. However the flows patients generate depend on the resistance of the device and on their own lung function. In-house in vitro data comparing the HRes inhaler with Bronchitol at 45 and $60 \mathrm{~L} / \mathrm{min}$ showed that the fine particle dose (FPD) was the same at both flow rates. The decision to use the HRes device for the phase III CF trials and as the device of choice for non-CF bronchiectasis studies was made following patient feedback on ease of use and tolerability of the HRes device, making it the most suitable for frequent administration of inhaled mannitol over the long-term.

In vitro testing of the device for delivered dose uniformity (DDU) and aerodynamic particle size distribution

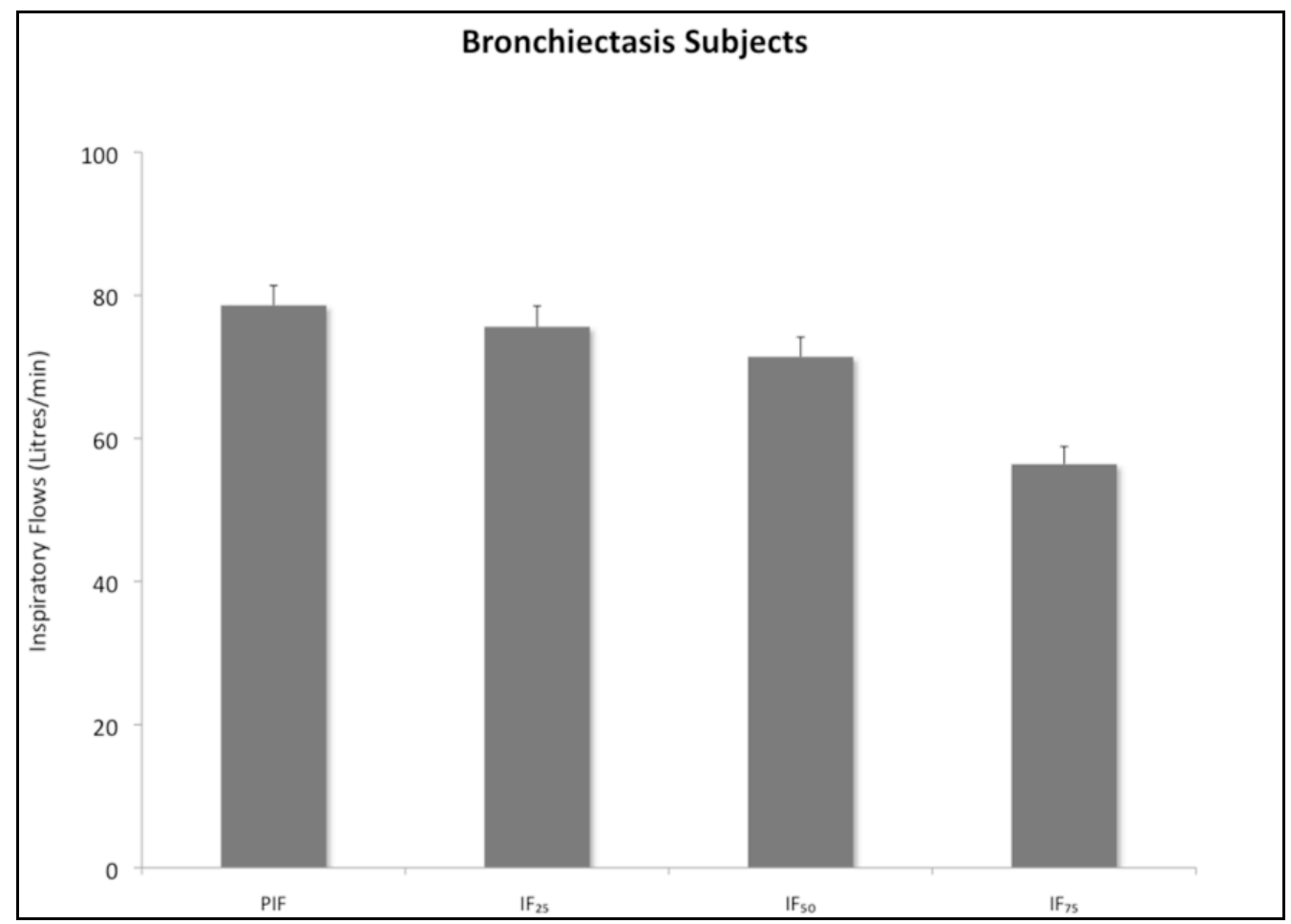

Fig. (2). Mean (+SEM) inspiratory flows measured with high resistance inhaler in 17 non-CF bronchiectasis subjects. PIF - Peak inspiratory flow, $\mathrm{IF}_{25}$ - Inspiratory flow at $25 \%$ inspiratory volume, $\mathrm{IF}_{50}$ - Inspiratory flow at $50 \%$ inspiratory volume, $\mathrm{IF}_{75}$ - Inspiratory flow at $75 \%$ inspiratory volume. 


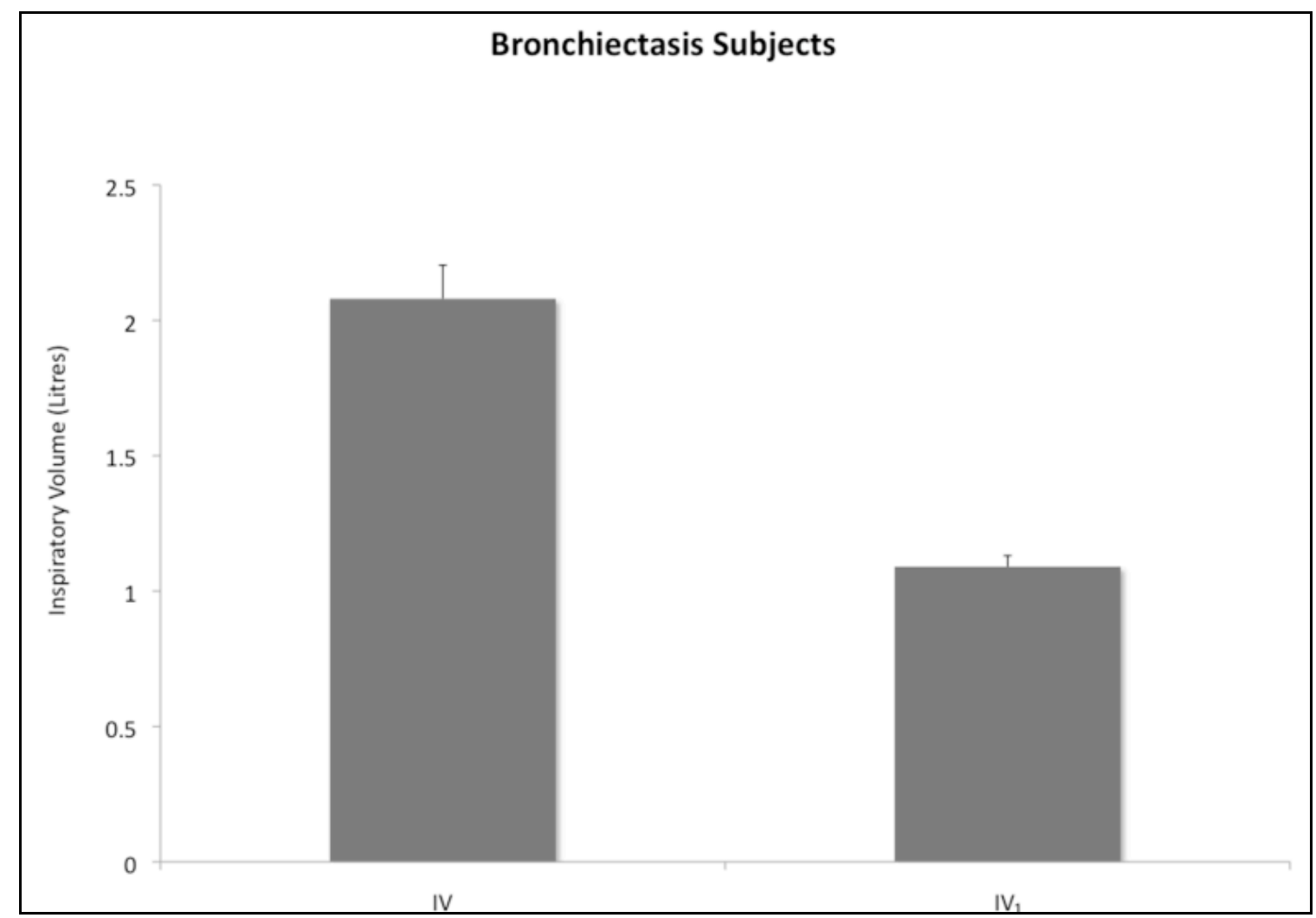

Fig. (3). Mean (+SEM) inspiratory volumes measured with high resistance inhaler in 17 non-CF bronchiectasis subjects. IV - Inspiratory volume, $\mathrm{IV}_{1}$ - Inspiratory volume in 1 second.

(APSD) of dry powder mannitol, in accordance with the European Pharmacopoeia (Ph.Eur.) [10] and United States Pharmacopeia (USP) [11], showed that the HRes device gave comparable delivered dose and APSD between 45 and $100 \mathrm{~L} / \mathrm{min}$. The Fine Particle Dose $(<5 \mu \mathrm{m})$ test results were all within a range of $\pm 6 \%$ and the MMAD (mass median aerodynamic diameter) results were all within a range of 3.9 to $4.1 \mu \mathrm{m}$ when using the standard test volume of $4 \mathrm{~L}$. The mean delivered dose test results were all within a range of $\pm 13 \%$ when using test volumes of $1 \mathrm{~L}$ to $4 \mathrm{~L}$ [Pharmaxis data on file]. Lower flow rates and volumes tested in vitro resulted in lower delivered doses. The delivered dose was reduced by approximately $20 \%$ at $28 \mathrm{~L} / \mathrm{min}$ when using an inhalation volume of $2 \mathrm{~L}$. When the inhalation volume was reduced to $1 \mathrm{~L}$ at $28 \mathrm{~L} / \mathrm{min}$ the reduction in the delivered dose was approximately $35 \%$.

All non-CF bronchiectasis subjects generated a PIF above $45 \mathrm{~L} / \mathrm{min}$ with adequate volume and inspiratory flows (PIF, $\mathrm{IF}_{25}, \mathrm{IF}_{50}$ and $\mathrm{IF}_{75}$ ) necessary for proper dispersion of dry powder medication and emptying of the capsules. Midflow rates were also adequate. There were no discernable differences based on $\mathrm{FEV}_{1}$ at baseline (5 subjects with $\geq 50 \%$ to $<70 \%$ predicted and 12 subjects with $\geq 70 \%$ predicted). These findings are in agreement with those of other researchers regarding inspiratory flow from dry powder inhalers $[4,12,13]$.

In this study subjects practiced taking a deep and steady inhalation at $60 \mathrm{~L} / \mathrm{min}$. We were simply interested in the flows that subjects generated without maximum efforts. The rate of rise of inhalation flow was not measured and its effect on the deaggregation of mannitol for optimal MMAD is not known. It has been shown though that the inhalation flow profile is very reproducible within the same individual but highly variable between individuals [14]. While the rate of rise of inhalation flow did not correlate with the deposited mannitol in the lung, the mannitol deposited in the lung did correlate with the peak inspiratory flow [14]. Based on the results of the $\mathrm{IF}_{25}, \mathrm{IF}_{50}$ and $\mathrm{IF}_{75}$, it is obvious that the highest IF was achieved in the first $50 \%$ of the IV (Table 2 ).

Sufficient inspired volume is necessary for emptying the capsule. All the non-CF bronchiectasis subjects had inspired volume greater than $1 \mathrm{~L}$. In clinical practice it is recommended that patients check to see that the capsule has emptied and if not then the inhalation should be repeated until the capsule appears empty. The ERS/ISAM Task force recommend a second inhalation when the powder is in capsules, as is the case with mannitol [15].

\section{CONCLUSION}

Together with in vitro laboratory testing for dose uniformity and aerodynamic particle size distribution for dry powder mannitol, this study confirms that subjects with nonCF bronchiectasis were able to generate the inspiratory flows and volumes necessary to successfully operate the RS01 DPI designed for the inhalation of mannitol.

Trial registration: ClinicalTrials.gov Identifier: NCT00656565.
ABBREVIATIONS
APSD = Aerodynamic particle size distribution
$\mathrm{CF} \quad=$ Cystic fibrosis 


$$
\begin{array}{ll}
\mathrm{CT} & =\text { Computed tomography } \\
\mathrm{DDU} & =\text { Delivered dose uniformity } \\
\mathrm{DPI} & =\text { Dry powder inhaler } \\
\mathrm{FEV}_{1} & =\text { Forced expiratory volume in } 1 \text { second } \\
\mathrm{FPD} & =\text { Fine particle dose } \\
\mathrm{HRCT} & =\text { High-resolution computed tomography } \\
\mathrm{HRes} & =\text { High resistance inhaler } \\
\mathrm{IF} & =\text { Inspiratory flow } \\
\mathrm{IV} & =\text { Inspiratory volume } \\
\mathrm{IV} & =\text { Inspiratory volume in one second }\left(\mathrm{IV}_{1}\right) \\
\mathrm{L} & =\text { Litre } \\
\mathrm{LRes} & =\text { Low resistance inhaler } \\
\text { MMAD } & \text { Mass median aerodynamic diameter } \\
\text { PIF } & =\text { Peak inspiratory flow } \\
\text { SD } & =\text { Standard deviation } \\
\mathrm{USP} & =\text { United States Pharmacopeia }
\end{array}
$$

\section{CONFLICT OF INTEREST}

The authors declare that there are no conflicts of interest.

\section{ACKNOWLEDGEMENTS}

\section{Author's Role}

All authors helped to interpret data, write the manuscript and have seen and approved the final version.

Dr. Charlton designed the study, approved the statistical plans and was the Sponsor's Responsible Medical Officer. $\mathrm{He}$ is also identified as the guarantor of the paper, taking responsibility for the integrity of the work as a whole, from inception to published article. Drs. Anderson and Elkins were the Investigators at the investigational site and had full access to all the data in the study and have no conflict to disclose relevant to this manuscript. Their institute received standard clinical trial support from Pharmaxis. No Investigator received any personal funding to participate in the study. Ms Perry worked on the OSM402 Non-CF bronchiectasis study. Dr. Daviskas helped with the preparation of the manuscript.

Dr. Anderson, Clare Perry and Dr. Daviskas are employed by Sydney South West Area Health Service. All hold shares in Pharmaxis Ltd that they purchased but they do not hold any options.

Dr. Charlton is the Medical Director of and holds stock options in Pharmaxis Ltd.

\section{Funding}

Pharmaxis Ltd.

\section{Role of the Funding Source}

The study sponsor participated in the study design, data collection, data analysis, data interpretation and writing of the reports. Following completion of the trials, the data were held and analysed by the sponsor. All authors had full access to all data and Mark Elkins had final responsibility for the publication.

We thank Ruth Martens who worked on the flow studies for Pharmaxis and Carina Flodin, Development and Technical Services Co-ordinator at Pharmaxis.

\section{REFERENCES}

[1] Glover W, Chan H-K, Eberl S, Daviskas E, Verschuer J. Effect of particle size of dry powder mannitol on the lung deposition in healthy volunteers. Int J Pharm 2008; 349: 314-22.

[2] Quanjer PH, Tammeling GJ, Cotes JE, Pedersen OF, Peslin R, Yernault JC. Lung volumes and forced ventilatory flows. Eur Respir J 1993; 6(Suppl 16): 5-40.

[3] Miller MR, Hankinson J, Brusasco V, et al. Standardisation of spirometry. Eur Respir J 2005; 26: 319-38.

[4] Tiddens HA, Geller DE, Challoner P, et al. Effect of dry powder inhaler resistance on the inspiratory flow rates and volumes of cystic fibrosis subjects of six years and older. J Aerosol Med 2006; 19: 456-65.

[5] Clark AR, Hollingworth AM. The relationship between powder inhaler resistance and peak inspiratory conditions in healthy volunteers - Implications for in vitro testing. J Aerosol Med 1993; 6: 99-110.

[6] Terzano C, Colombo P. State of the art and new perspectives on dry powder inhalers. Eur Rev Med Pharm Sci 1999; 3: 247-54.

[7] Chew NYK, Chan H-K. Influence of particle size, airflow, and inhaler device on the dispersion of mannitol as aerosols. Pharmacol Res 1999; 16: 1098-103.

[8] Chew NYK, Chan H-K. In vitro Aerosol performance and dose uniformity between the Foradile Aerolizer and the Oxis Turbuhaler. J Aerosol Med 2001; 14: 495-501.

[9] Broeders MEAC, Molema J, Vermue NA, Folgering HT. Peak inspiratory flow rate and slope of the inhalation profiles in dry powder inhalers. Eur Respir J 2001; 18: 780-83.

[10] European Pharmacopoeia (Ph. Eur.)

[11] United States Pharmacopeia (USP).

[12] Kanabuchi K, Kondo T, Tanigaki T, et al. Minimal inspiratory flow from dry powder inhalers according to a biphasic model of pressure vs flow relashionship. Tokai J Exp Clin Med 2011; 39: 1-4.

[13] Gauld LM, Briggs K, Robinson P. Peak inspiratory flows in children with cystic fibrosis. J Paediatr Child Health 2003; 39: 21013.

[14] Glover W, Chan H-K, Eberl S, Daviskas E, Anderson S. Lung Deposition of mannitol powder aerosol in healthy subjects. J Aerosol Med 2006; 19: 522-32.

[15] Laube BL, Janssens HM, de Jongh FHC, et al. ERS/ISAM Task Force Report. What the pulmonary specialist should know about the new inhalation therapies. Eur Respir J 2011; 37: 1308-31. 